\title{
An Outbreak of Ovine Listeriosis in Qassim Region, Saudi Arabia: Epidemiological, Clinical and Treatment Outcomes
}

\author{
Salama A. Osman ${ }^{1,2 *}$, Mohamed Tharwat ${ }^{1,3}$ and Elhassan M.A. Saeed ${ }^{1,4}$ \\ ${ }^{1}$ Department of Veterinary Medicine, College of Agriculture and Veterinary Medicine, Qassim University, P.O. Box 6622, \\ Buraidah, 51452, Saudi Arabia \\ ${ }^{2}$ Department of Animal Medicine, Faculty of Veterinary Medicine, Kafrelsheikh University, Egypt \\ ${ }^{3}$ Department of Animal Medicine, Faculty of Veterinary Medicine, Zagazig University, Egypt \\ ${ }^{4}$ Department of Microbiology, Faculty of Veterinary Medicine, University of Khartoum, Sudan \\ *Corresponding author: salama2068@yahoo.com
}

Article History: 21-286 Received: 28-Feb-21 Revised: 28-Apr-21 Accepted: 04-May-21
ABS TRACT
This study was carried out to describe the epidemiological, clinical and treatment outcomes of an outbreak of listeriosis
in a sheep flock at Qassim Region, central of Saudi Arabia during January 2020 . The flock consisted of 700 sheep of
different age and sex. The overall morbidity rate was $57.14 \%$, while the mortality rate was $50 \%$ and the case fatality
rate was $87.5 \%$. The morbidity rate was statistically lower (P=0.0001) in sheep having age less than 6 months $(16.66 \%)$
than those over 6 months ( $74.48 \%)$. On the contrary, the case fatality rate was not statistically different (P=0.9) in young
sheep ( $97.14 \%)$ compared to adult animals $(86.57 \%)$. The clinical signs observed were acute deaths, nervous
manifestation in the form of staggers, ataxia, head tilt and circling. Initial diagnosis was made on the basis of the typical
clinical signs, while confirmatory diagnosis was made on the basis of bacteriological examination. Treatment using
penicillin as antibiotic in addition to flunixin meglumine as anti-inflammatory gave good results in case of early
intervention whereas late-stage treatment gave bad prognosis. So, early intervention is the key to treatment success.

Key words: Listeriosis, Sheep, Outbreak, Treatment.

C202I IJVS - All Rights Reserved

\section{INTRODUCTION}

Listeriosis is a highly fatal infectious disease caused by different Listeria (L.) species, but mainly by $L$. monocytogenes, affecting a lot of mammals, including different animal species as cattle, sheep, horses, dogs and humans (Fentahun and Fresebehat 2012). L. monocytogenes is a Gram-positive intracellular bacterium causing fatal meningoencephalitis in humans and ruminants (Pfister et al. 2002). It is considered as a significant food borne pathogen present in the surrounding environment. Moreover, ruminant animals are mainly the natural hosts for the microorganism where, these species can disseminate the microorganism through milk and meat (Shamloo et al. 2019; Rodriguez et al. 2021; Zhao et al. 2021).

Sheep is the most affected animal species representing clinical features in the form of septicemic, nervous, abortive, mastitis and gastroenteritis (Smith, 2001; Brugere-Picoux 2008; Limmahakhun and Chayakulkeeree 2013; OIE 2014). The disease has a worldwide distribution, particularly in temperate climates and favorable environmental conditions for growth of the microorganism such as bad quality silage (McLauchlin 1987; Fenlon 1988, 1999).

Ingestion of bad quality silage is considered the main route of infection particularly common in ruminants (Low and Donachie 1997). The microorganism can affect many organs as intestine especially in young animals and monogastric animals, reproductive systems and nervous system. So, the disease manifest itself in three forms namely, septicemia, abortion and encephalitis (Nash et al. 1995). Transmission of listeriosis from animals to humans has been associated either with ingestion of fecal contaminated food (Blenden et al. 1987; Pearson and Marth 1990) or directly from infected ruminants to man (Blenden et al. 1987). The economic losses of listeriosis are high, not only due to the losses in animal production but also due to the public health concern (Blenden et al. 1987; Pearson and Marth 1990).

Listeria monocytogenes, which is a foodborne bacterium is a major agent responsible for infectious diseases in humans and animals. In human, listeriosis occurs as sporadic cases, which is epidemiologically linked with

Cite This Article as: Osman SA, Tharwat M and Saeed EMA, 2021. An outbreak of ovine listeriosis in Qassim region, Saudi Arabia: Epidemiological, clinical and treatment outcomes. International Journal of Veterinary Science 10(4): 312316. https://doi.org/10.47278/journal.ijvs/2021.060 
consumption of contaminated food products. The signs of listeriosis in humans ranged from mild self-limiting disease to severe systemic infections in susceptible people (Ranjbar and Halaji 2018). Milk and dairy products from infected animals may resulted in life threatening diseases in a large population of people (Shamloo et al. 2019).

There is a little literature concerning listeria infection in Saudi Arabia in farm animals, so far, only two reports have been documented. The first was an outbreak in a sheep flock in the eastern region (Al-Dughaym et al. 2001) and the second was a case of cerebral listeriosis in she camel in the eastern region as well (Al-Swailem et al. 2010). So, this report is the third and it is about an outbreak occurred in a new area, Qassim Region, central region of Saudi Arabia. This study was carried out to describe the epidemiological, clinical and treatment outcomes of an outbreak of listeriosis in a sheep flock.

\section{MATERIALS AND METHODS}

\section{Ethical Approval}

Animal Ethical Committee, Scientific Research Deanship, the University of Qassim, Saudi Arabia approved this study.

\section{Animals and Sample Collection}

This investigation was done in winter (January 2020), on sheep flock consisted of 700 sheep of different age and sex belonging to a private farm at Qassim Region, central of Saudi Arabia. Animals were let to graze during the day and kept in pens and provided with fodder rolls (barley, grass, alfa alfa) during the night.

\section{Epidemiological and Clinical Investigation}

All sheep in this study were carefully examined clinically (Rosenberger 1979). Morbidity, mortality and case fatality rates were estimated epidemiologically according to the method described by Martin et al. (1987).

\section{Specimens for Bacteriological Examination}

Specimens of brain and liver tissues were aseptically collected from several clinical cases in sterile containers and immediately sent for laboratory investigation.

\section{Bacteriological Examination}

Bacterial isolation was attempted from the sterile tissue samples obtained from hind brain and liver tissues. Direct smears were stained by Gram's staining method. Specimens from the brain and liver were cultured on blood agar, MacConkey agar and brain heart infusion broth and agar. Samples were incubated at $37^{\circ} \mathrm{C}$ for $48 \mathrm{~h}$. Blood agar and brain heart infusion broth were also inoculated and incubated at $4{ }^{\circ} \mathrm{C}$ for six weeks with weekly examination of growth and subculture of broth on solid medium and incubation at $37^{\circ} \mathrm{C}$. The colonial characters of $L$. monocytogenes were observed on blood agar and MacConkey agar. Further characterization of $L$. monocytogenes was done according to catalase test, umbrella motility in semi-solid medium, tumbling motility in $3 \mathrm{~h}$ broth culture at $25^{\circ} \mathrm{C}$ by hanging drop technique and CAMP test (McKellar 1994).

\section{Therapeutic Intervention}

Diseased sheep was treated using penicillin-streptomycin (Pen \& Strep, NorBrook) administered by deep intramuscular once daily for 7 consecutive days at doses of $8 \mathrm{mg}$ procaine penicillin and 10mg dihydrostreptomycin sulphate per $\mathrm{kg}$ bodyweight achieved by administering $1 \mathrm{ml} / 25 \mathrm{~kg}$ BW. Flunixin meglumine (Finadyne, ScheringPlough) as anti-inflammatory agent was administered at a dose of $2.2 \mathrm{mg} / \mathrm{kg}$ body weight achieved by administration of $2 \mathrm{ml} / 45 \mathrm{~kg}$ BW. Sulphadiazine Sodium-trimethoprim (Joprim, Jordan Veterinary and Agriculture Medical Industrial Company) was administered at a dose of $1 \mathrm{gm} /$ $15 \mathrm{~kg} \mathrm{BW}$, daily for 5 days to healthy in-contact animals.

\section{Statistical Analysis}

The obtained data were analyzed by Chi-Square and $t$ test using the SPSS for Windows (2009) statistical software program and a $\mathrm{P}$ value of less than 0.05 was considered significant.

\section{RESULTS}

Out of the examined (700) sheep, 400 animals (57\%) showed nervous manifestation representing a morbidity rate $57.14 \%$. Out of these 400 sheep, 350 were died representing mortality rate of $50 \%$ and case fatality rate of $87.5 \%$ (Fig. 1).

The incidence of the disease in this study was lower in young sheep less than 6 months than those over 6 months The morbidity and mortality rates in young sheep were $16.66 \%(35 / 210)$ and $16.19 \%(34 / 210)$ compared to $74.48 \%(365 / 490)$ and $64.48 \%$ (316/490) respectively in animals over 6 months. On contrary, the case fatality rate was $97.14 \%$ (34/35) in young sheep compared to $86.57 \%$ (316/365) in adult ones (Fig. 1).

In the early stages of the disease, the sick animals were moving aimlessly with deviated neck. With progression of disease, animals showed unilateral cranial nerve deficits and started moving in circles. Severe depression, ataxia and circling were observed in all cases. Blindness was observed in 100 cases without any eye lesions. Abortion was occurred in 5 out of 80 pregnant ewes. Fever $\left(41-42^{\circ} \mathrm{C}\right)$ was observed only at the early stages of the disease, whereas in the late stages, the temperature was normal. Before death, the infected animals became recumbent, unable to eat and paddling of the forelimbs. Deaths were occurred within 10 days from the disease onset.

Microscopical examination of Gram-stained smears, prepared from solid medium, revealed Gram-positive short rods, coccobacilli or coccoid forms (Fig. 2). After 48 hours of incubation at $37^{\circ} \mathrm{C}$ on sheep blood agar, greyish white small dew drops like colonies with narrow slight clearing zones of $\beta$-hemolysis were observed. It was catalasepositive and cells were motile at $25^{\circ} \mathrm{C}$.

In this study, the results of the treatment revealed that, early intervention using penicillin (administered by deep intramuscular daily once for 7 consecutive days) in addition to Flunixin meglumine as anti-inflammatory agent gave good results. However, administration of the drug in late stages of the disease had no effects. Sulphadiazine Sodium-trimethoprim offered to all healthy sheep as a method of control gave good efficacy in lowering the occurrence of new cases. 


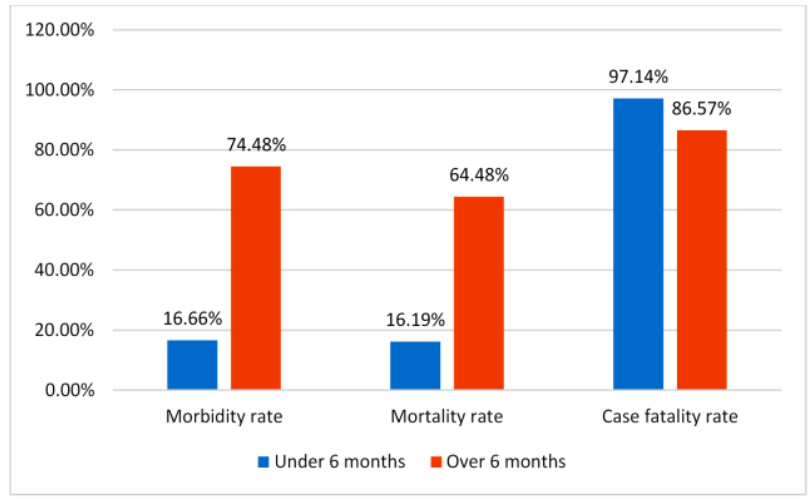

Fig. 1: Morbidity, mortality and case fatality rates during the outbreak.

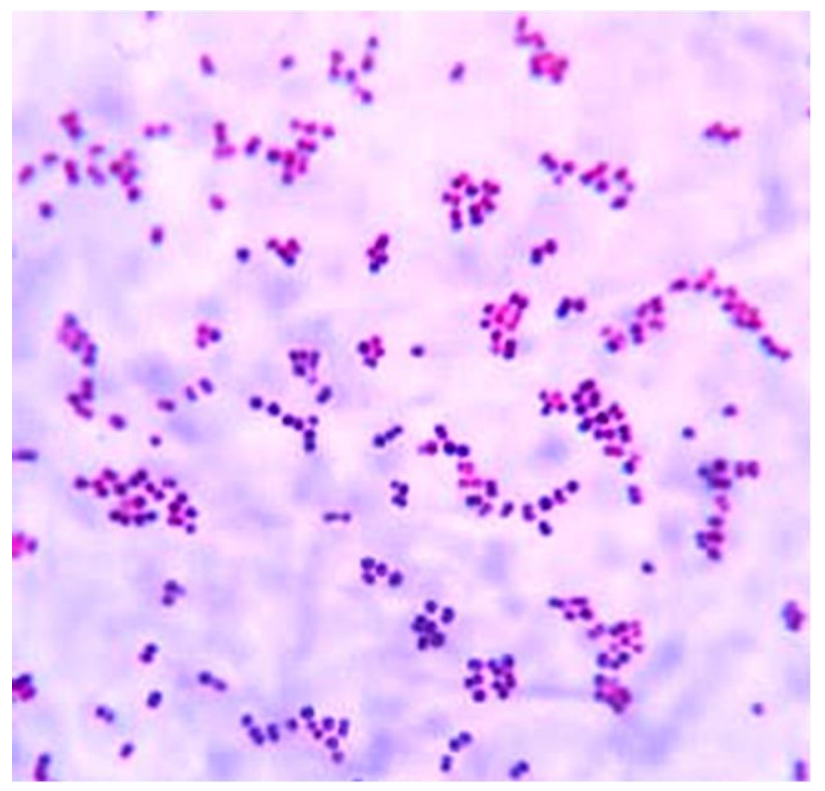

Fig. 2: Gram-stained smears showing Gram-positive short rods, coccobacilli or coccoid forms.

\section{DISCUSSION}

Listeriosis is one of the most important infectious diseases of most animal species with zoonotic importance worldwide; it has considerable economic significance as it is mainly a foodborne pathogen (Barman et al. 2020). Listeriosis is an infection characterized by high case fatality rate. All of domestic animals can attract the disease, but cattle and sheep are the most commonly affected (Cooper and Walker, 1998). In this study, the morbidity rate was $57.14 \%$, the mortality rate was $50 \%$ and the fatality rate was $87.5 \%$. Variations in these rates were recorded in the previous outbreaks, where Vandegraaff et al. (1981) recorded morbidity rate ranged from 0.2 to $8.0 \%$, and $100 \%$ fatality rate. Nash et al. (1995) reported that 3.1 and $1.3 \%$ of ewes and lambs were died from listeriosis subsequently. Al-Dughaym et al. (2001) found that the disease was observed in adult animals, mostly pregnant ewes with a morbidity rate of $7.1 \%$ and mortality rate of $2.4 \%$. George (2002) mentioned that the incidence rate might reach $9 \%$, but rarely over $2 \%$. These variations may be attributed to the differences in the animal susceptibility in different areas.
The high mortality rate that was observed in this outbreak may be due to the occurrence of the infection for the first time in this area in highly susceptible animals, free from any source of previous immunity due to no vaccination or previous exposure. Also, the misdiagnosis of the infection as coenurosis by the owners and using of anti-parasitic drug instead of antibiotics aggravated the problem. The morbidity and mortality rates in sheep less than 6 months (16.66 and 16.19\%) were statistically lower $(\mathrm{P}=0.0001)$ than those in sheep more than 6 months 74.48 and $64.48 \%$. This may be referred to the feeding of young animals on milk mainly. On contrary, the case fatality rate was not statistically different $(\mathrm{P}=0.9)$ in young sheep $(97.14 \%)$ than that in adult ones (86.57\%). Similar observation was recorded by Nash et al. (1995) and Kumar et al. (2007). The high case fatality rates in late treated sheep may be attributed to the irreversible injuries and limited repair capacity for the brain (Niederkorn 2006).

L. monocytogenes is major widespread zoonoses, especially in domestic animals. It is found commonly in the soils, decaying vegetation, and as fecal flora of some mammals (Schuchat et al. 1991; Bille et al. 2003). About $5 \%$ of healthy adult animals carry the microorganism in their feces (Schlech et al. 1983; Schuchat et al. 1991), these healthy carriers were documented in different species of animals (Low and Donachie 1997). In particular, subclinically mastitic animals due to L. monocytogenes can excrete the microorganism in their milk (Fthenakis et al. 1998; Wagner et al. 2000).

The outbreak in this study was occurred in winter season. Similar observations were reported previously by Nash et al. (1995), Al-Dughaym et al. (2001) and Radostits et al. (2007) who reported that the occurrence of listeriosis outbreaks was mainly during winter and within 2 weeks after the introduction of silage. This may be referred to the wide scale of temperature $\left(4\right.$ to $\left.37^{\circ} \mathrm{C}\right)$, with the fastest growth rates occurring at 30 to $37^{\circ} \mathrm{C}$. Several factors including abrupt changes in food, extremely cold weather, transportation and lactation lower the host immunity and increase the animal susceptibility to infection. Feeding of sheep on bad quality silage had an immunosuppressive effect and make animal more reliable to infection (BrugerePicoux 2008).

The clinical signs of listeriosis may be septicemic, nervous or abortive according to the tissue affected (Scott 2013). In the present study, the clinical signs observed in infected sheep were in the form of nervous manifestation. Deaths were occurred within 10 days from the disease onset. Similar clinical signs were also recorded previously (Low and Linklater 1985; Smith and Sherman 1994; Rebhun 1995; Low and Donachie 1997; Braun et al. 2002; Mahajan et al. 2020). The observed nervous signs may be attributed to the proliferation of L. monocytogenes within the subarachnoid and ventricular space which produced a severe host inflammatory response resulting in bacterial lysis in the CSF and release of bacterial components which stimulate the release of neuro-inflammatory molecules and other pro-inflammatory host proteins (Yadav et al. 2009). Barlow and McGorum (1985) postulated that the organism reached the brain by way of circulating blood or branches of the trigeminal nerve that terminated in the oral cavity, nasal cavity or conjunctiva. Moreover, as a result of the facial and tongue paralysis, undigested food was observed inside the animal mouth (Kumar et al. 2007). 
The microscopic examination of Gram-stained smears, prepared from solid medium, demonstrated Gram-positive short rods, coccobacilli or coccoid forms. The suspected colonies were identified on the bases of being $\beta$-hemolytic, catalase-positive, and cells were motile at $25^{\circ} \mathrm{C}$.

Confirmatory diagnosis in this study was mainly based on the bacteriological examination in animal specimens. This procedure is the most accurate confirmatory tool for diagnosis to which other methods are compared (Quinn et al. 1999). Gram-stained smears revealed Gram-positive short rods, coccobacilli or coccoid forms. The suspected colonies were identified on the bases of being $\beta$-hemolytic, catalase-positive, and cells were motile at $25^{\circ} \mathrm{C}$. Similar observation was recorded previously by Kumar et al. (2007).

In this outbreak, infected sheep were not admitted to silage feeding indicating that infection by listeriosis in sheep can occur without feeding on silage. Similar observation was recorded by Kumar et al. (2007) who concluded that ovine listeriosis outbreaks can be happened without the association with the feeding on silage. This may be explained by the wide occurrence of $L$. monocytogenes in the environment other than silage such as soil, water, sewage, wild animal feces and the fecal matter of some normal animals. Under stress factors, $L$. monocytogenes can convert to pathogenic type causing clinical disease (Sauders and Wiedmann 2007; BrugerePicoux 2008).

In this study, the results of the treatment revealed that, early intervention using penicillin in addition to flunixin meglumine as anti-inflammatory agent gave good results. However, administration of these drugs in late stages of the disease gave no effects. Similar observation was reported by Radostits et al. (2007) who recorded that listeriosis had a per-acute course causing rapid deaths within 2-4 days and treatment is often not effective.

Low and Donachie (1997) reported that antibiotics such as penicillin or tetracycline can be used successfully in the treatment of listeriosis. Hof (2003) found all commonly used antibiotics, except cephalosporins were active against $L$. monocytogenes in vitro and amoxicillin and gentamicin combination was the best choice. In the present study, Sulphadiazine Sodium-trimethoprim was offered to all healthy sheep in drinking water as a method of control and gave good efficacy in lowering the occurrence of new cases. Hawkins et al. (1984) found that the use of trimethoprim-sulfamethoxazole combination was superior to either drug alone.

\section{Conclusion}

It is concluded that, ovine listeriosis in Saudi Arabia could pose a significant public health concern where meat, milk or meat products from sheep are widely used by the people and so listeriosis in Saudi Arabia must take a great attention. Also, early intervention using penicillin is the key to treatment success. Moreover, Sulphadiazine Sodium-trimethoprim administration orally to healthy incontact sheep during the outbreak as a method of control gave good efficacy in lowering the occurrence of new cases.

\section{Author's Contribution}

All authors contributed equally to this study.

\section{REFERENCES}

Al-Dughaym AM, Elmula AF, Mohamed GE, Hegazy AA, Radwan YA, Housawi FMT and Gameel AA, 2001. First report of an outbreak of ovine septicaemic listeriosis in Saudi Arabia. Revue Scientifique Et Technique-Office International Des Epizooties 20: 777-783. https://doi.org/ $\underline{10.20506 / \text { rst.20.3.1312. }}$

Al-Swailem AA, Al-Dubaib MA, Al-Ghamdi G, Al-Yamani EA, Al-Naeem AM, Al-Mejali A, Shehata M, Hashad ME, Aboelhassan DE and Mahmoud OM, 2010. Cerebral listeriosis in a she-camel at Qassim Region, Central Saudi Cerebral listeriosis in a she-camel at Qassim Region, Central Saudi Arabia - a case report Arabia - a case report. Veterinarski Arhiv 80: 539-547. https://hrcak.srce.hr/58468.

Barman NN, Nath AJ, Doley S, Begum SA, Kakati P, Das SK, Rahman T, Bhuyan D, Baishya BC and Goswami S, 2020 Listeriosis in a peri-urban area: Cultural and molecular characterization of Listeria monocytogenes isolated from encephalitic goats. Veterinary World 13: 1743-1749. https://doi.org/10.14202/vetworld.2020.1743-1749.

Barlow RM and McGorum B, 1985. Ovine listerial encephalitis: analysis, hypothesis and synthesis. Veterinary Record 116: 233-236. https://doi.org/10.1136/vr.116.9.233.

Bille J, Rocourt J and Swaminathan B, 2003. Listeria and Erysipelothrix. In: Murray PR, Baron EJ, Jorgensen JH et al (eds) Manual of Clinical Microbiology, $8^{\text {th }}$ Ed. ASM, Washington DC, pp: 461-471.

Blenden D, Kampelmacher E and Torres-Anjel M, 1987. Listeriosis. Journal of American Veterinary Medical Association 191: 1546-1551.

Braun U, Stehle C and Ehrensperger F, 2002. Clinical findings and treatment of listeriosis in 67 sheep and goats. Veterinary Record 150: 38-42. https://doi.org/10.1136/vr.150.2.38.

Brugere-Picoux J, 2008. Ovine listeriosis. Small Ruminant Research 76: 12-20. https://doi.org/10.1016/j.smallrumres. 2007.12.022.

Cooper J and Walker RD, 1998. Listeriosis. Veterinary Clinics of North America. Food Animal Practice 14: 113-125. https://doi.org/10.1016/S0749-0720(15)30283-8.

Fenlon DR, 1988. Listeriosis. In: Silage and Health. Stark BA and Wilkinson JM (eds). Proceedings of a conference held at Bristol Veterinary School, Langford, Bristol Marlow, UK, pp: 7-17.

Fenlon DR, 1999. Listeria monocytogenes in the natural environment. In Listeria, Listeriosis and Food Safety, $2^{\text {nd }}$ Ed. In: Ryser ET and Marth EH (eds), Marcel Dekker, New York, USA, pp: 21-37.

Fentahun $\mathrm{T}$ and Fresebehat A, 2012. Listeriosis in small ruminants: A review. Advances in Biological Research 6: 202-209.

Fthenakis GC, Saratsis PH, Tzora A and Linde K, 1998. Naturally occurring subclinical ovine mastitis associated with Listeria monocytogenes, Small Ruminant Research 31: 23-27. https://doi.org/10.1016/S0921-4488(98)00118-7.

George LW, 2002. Listeriosis. In: Smith BP (ed), Large Animal Internal Medicine. Mosby, St Louis pp: 946-949.

Hawkins AE, Bortolussi R and Issekutz AC, 1984. In vitro and in vivo activity of various antibiotics against Listeria monocytogenes type $4 \mathrm{~b}$. Clinical and Investigative Medicine $7: 335$.

Hof H, 2003. Therapeutic options. FEMS Immunology and Medical Microbiology 35: 203-205. https://doi.org/10.1016/ s0928-8244(02)00466-2.

Kumar H, Singh BB, Bal MS, Kaur K, Singh R, Sidhu PK and Sandhu KS, 2007. Pathological and epidemiological investigations into listerial encephalitis in sheep. Small Ruminant Research 71: 293-297. https://doi.org/10.1016/ j.smallrumres.2006.05.010. 
Limmahakhun S and Chayakulkeeree M, 2013. Listeria monocytogene brain abscess: two cases and review of the literature. The Southeast Asian Journal of Tropical Medicine and Public Health 44: 468-478.

Low C and Linklater K, 1985. Listeriosis in sheep, In Practice 7: 66-67. https://doi.org/10.1136/inpract.7.2.66.

Low JC and Donachie W, 1997. A review of Listeria monocytogenes and listeriosis. The Veterinary Journal 153: 9-29. https://doi.org/10.1016/S1090-0233(97)80005-6.

Mahajan V, Bal MS, Filia G, Leishangthem GD and Sandhu KS, 2020. Diagnosis of encephalitic listerial outbreak in sheepimmunohistopathological study. International Journal of Current Microbiology and Applied Sciences 9: 3235-3238. https://doi.org/10.20546/ijcmas.2020.906.386.

Martin SW, Meek AH and Willeberg P, 1987. Veterinary Epidemiology. Principles and Methods. Iowa State University Press, Ames, Iowa.

McKellar RC, 1994. Use of the CAMP test for identification of Listeria monocytogenes. Applied and Environmental Microbiology 60: 4219-4225.

McLauchlin J, 1987. Listeria monocytogenes, recent advances in the taxonomy and epidemiology of listeriosis in humans. Journal of Applied Bacteriology 63: 1-11. https://doi.org/ 10.1111/j.1365-2672.1987.tb02411.x.

Nash ML, Hungerford LL, Nashb TG and Zinn GM, 1995. Epidemiology and economics of clinical listeriosis in a sheep flock. Preventive Veterinary Medicine 24: 147-156. https://doi.org/10.1016/0167-5877(95)00484-E.

Niederkorn JY, 2006. See no evil, hear no evil, do no evil: the lessons of immune privilege. Nature Immunology 7: 354-9. https://doi.org/10.1038/ni1328.

OIE, 2014. Listeria monocytogenes. Chapter 2.9.7. Manual of diagnostic tests and vaccines for terrestrial animals. pp: 1-18. Available from: http://www.oie.int/manual-of-diagnostictests-and-vaccines-for-terrestrialanimals.

Pearson L and Marth E, 1990. Listeria monocytogenes-threat to a safe food supply: a review. Journal of Dairy Science 73: 912928. https://doi.org/10.3168/jds.S0022-0302(90)78748-6.

Pfister H, Remer KA, Brcic M, Fatzer, R, Christen S, Leib S and Jungi TW, 2002. Inducible nitric oxide synthase and nitrotyrosine in listeric encephalitis: A cross-species study. Veterinary Pathology 39: 190-199. https://doi.org/ 10.1354\%2Fvp.39-2-190.

Quinn PJ, Carter ME, Markey B and Carter GR, 1999. The streptococci and related cocci. In: Quinn PJ, Carter ME, Markey B, Carter GR (eds), Clinical Veterinary Microbiology. Mosby International, Edinburgh, Scotland, pp: $127-136$.

Radostits OM, Gray CC, Hinchichiff KW and Constable PD, 2007. Veterinary Medicine, a Text Book of the Diseases of Cattle, Sheep, Pigs, Goats and Horses. $10^{\text {th }}$ Ed. Philadelphia: Saunders, pp: 1048-1050.

Ranjbar R and Halaji M, 2018. Epidemiology of Listeria monocytogenes prevalence in foods, animals and human origin from Iran: a systematic review and meta-analysis. BMC Public Health 18: 1057. https://doi.org/10.1186/ s12889-018-5966-8.
Rebhun WC, 1995. Diseases of dairy cattle, p. 410-413. Williams \& Wilkins, Media, Pa.

Rodriguez C, Taminiau B, García-Fuentes E, Daube G and Korsak N, 2021. Listeria monocytogenes dissemination in farming and primary production: Sources, shedding and control measures. Food Control 120: 107540. https://doi.org/ 10.1016/j.foodcont.2020.107540.

Rosenberger G, 1979. Clinical examination of cattle. A Text Book $3^{\text {rd }}$ Ed. Berlin, Praey, Germany.

Sauders BD and Wiedmann M, 2007. Ecology of Listeria species and L. monocytogenes in the natural environment. In: Ryser ET and Marth EH (eds), Listeria, listeriosis, and food safety. Marcel Dekker, New York, USA, pp: 21-53.

Schlech WF, Lavigne PM, Bortolussi RA, Allen AC, Haldane EV, Wort AJ, Hightower AW, Johnson SE, King SH, Nicholls ES and Broome C, 1983. Epidemic listeriosis-evidence for transmission by food. The New England Journal of Medicine 308: 203-206. https://doi.org/10.1056/nejm 198301273080407.

Schuchat A, Swaminathan B and Broome CV, 1991. Epidemiology of human listeriosis. Clinical Microbiology Review 4: 169-183. https://dx.doi.org/10.1128\%2Fcmr.4.2. 169.

Scott PR, 2013. Clinical diagnosis of ovine listeriosis Small Ruminant Research 110: 138-141. https://doi.org/10.1016/j. smallrumres.2012.11.002.

Shamloo E, Hosseini H, Abdi-Moghadam Z, Halberg-Larsen M, Haslberger A and Alebouyeh M, 2019. Importance of Listeria monocytogenes in food safety: A review of its prevalence, detection, and antibiotic resistance. Iranian Journal of Veterinary Research 20: 241-254.

Smith BP, 2001. Large Animal Internal Medicine, $3^{\text {rd }}$ Ed. Mosby, pp: 946-949.

Smith MC and Sherman DM, 1994. Goat Medicine. Lea \& Febiger, Malvern, PA, USA, pp: 141-144.

SPSS, 2009. Statistical Package for Social Sciences. Chicago, IL, USA: SPSS, Inc. Copyright for Windows, version 18.0.

Vandegraaff R, Borland NA and Browning JW, 1981. An outbreak of listerial meningo-encephalitis in sheep. Australian Veterinary Journal 57: 94-96. https://doi.org/ 10.1111/j.1751-0813.1981.tb00457.x.

Wagner M, Podstatzky-Lichtenstein L, Lehner A, Asperger H, Baumgartner W and Brandl E, 2000. Prolonged excretion of Listeria monocytogenes in a subclinical case of mastitis, Milchwissenschaft 55: 3-6.

Yadav A, Malik GK, Trivedi R, Prasad A, Nath K, Prasad KN, Agrawal P, Rathore RK, Tripathi RP and Gupta RK, 2009. Correlation of CSF neuroinflammatory molecules with leptomeningeal cortical subcortical white matter fractional anisotropy in neonatal meningitis. Magnetic Resonance Imaging 27: 214-221. https://doi.org/10.1016/j.mri.2008. $\underline{06.010}$

Zhao Q, Hu P, Li Q, Zhang S, Li H, Chang J, Jiang Q, Zheng Y, Li Y, Liu Z, Ren H and Lu S, 2021. Prevalence and transmission characteristics of listeria species from ruminants in farm and slaughtering environments in China. Emerging Microbes \& Infections. https://doi.org/ $\underline{10.1080 / 22221751.2021 .1888658 .}$ 